\title{
Research on grid connection control strategy for island microgrid with renewable energy resources
}

\author{
Deng Hua ${ }^{1, a^{*}, \text { Li Guanglei,b }}{ }^{2, b}$ Xing Hongwei ${ }^{3, c}$,Wang Qian ${ }^{4, d}$ and Shi Xinlei $i^{5, e}$ \\ ${ }^{1}$ State Grid Yantai Power Supply Company, Yantai, China \\ 2 State Grid Shandong Electric Power Research Institute, Jinan, China \\ ${ }^{3}$ Shandong Luneng Software Technology Co.,Ltd, Jinan, China \\ ${ }^{4}$ State Grid Zhangqiu Power Supply Company, Zhangqiu, China \\ ${ }^{5}$ State Grid Qufu Power Supply Company, Qufu, China \\ a214672717@qq.com, ${ }^{b}$ lovexjtulgl@126.com, c qianli917a@sina.com, d sdzhc@sohu.com, \\ eII@163.com
}

Keywords: control strategy; island microgrid; solution design; system test.

Abstract. The establishment of stable and reliable island microgrid with renewable energy resources is an important measure to guarantee the island economic development. The scheme and strategy is used to achieve information communication and interactive control. The energy storage unit and diesel generator can be coordinated control to ensure the system voltage and frequency stability and also reduces the risk of overloading the storage unit. The results show strategies proposed can ensure the system voltage and frequency stability and also reduces the risk of overloading the storage unit.

\section{Introduction}

China has 14000 kilometers of island coastline and more than 6961 islands sprawls over 500 acres [1][2].It are of great practical and strategic significance to develop and utilize comprehensively resources in islands. Therefore, the study on island grid with renewable energy resources is very meaningful. Research institutes have been having not carried out a detailed simulation analysis of stability of island microgrid under high penetration structure [3][4].This paper can be divided into three parts. First, propose the electrical structure of intermittent renewable energy island system, establish the analysis model of the key component. Secondly, analyzes the control strategy of grid in grid and island in two cases. Finally, the proposed control strategy is verified on the PSCAD simulation software.

\section{Modeling analysis}

The power grid structure of renewable sources The structure of island grid is shown as below. This system contains $35 \mathrm{kV}, 10 \mathrm{kV}$ two voltage levels and connects the large power grid through $110 \mathrm{kV}$ submarine cables. Under the condition of synchronization, $110 \mathrm{kV}$ line is the only source of island. When the grid broke down, $110 \mathrm{kV}$ submarine cables will switch turn off. So this island power grid will form an isolated system.

Island microgrid with renewable energy resources usually includes a variety of distributed power supply, such as Wind power, photovoltaic, energy storage and diesel generator. Distributed power comprises a significant proportion of tenants in island microgrid. Power load is divided into conventional load and seawater desalination load. The typical structure of intermittent renewable energy grid is shown in Fig.1. 


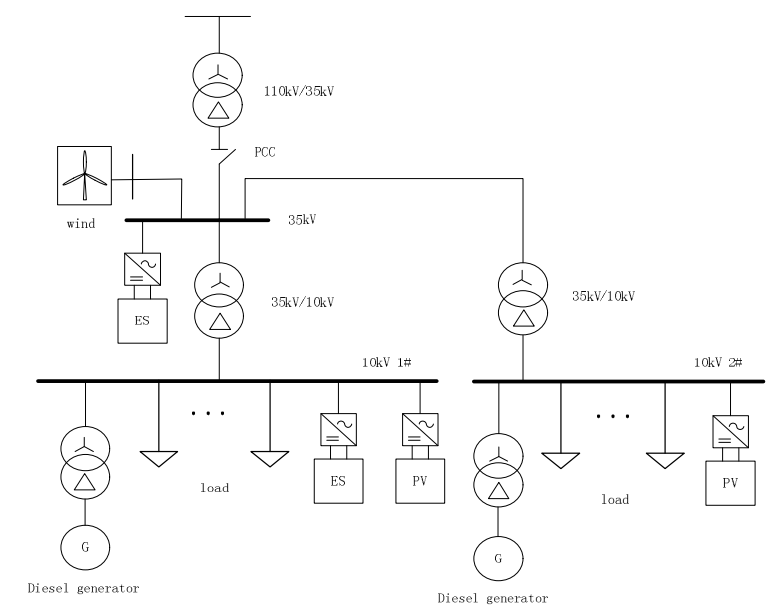

Fig.1 Power network structure of the renewable energy grid

Using PSCAD simulation platform, operation control strategies are justified under the conditions of the grid connection and island running. Composition of the island power grid is shown as the following table.

Table1 parameter list of the island grid

\begin{tabular}{|l|l|}
\hline \multicolumn{1}{|c|}{ Voltage } & \multicolumn{1}{c|}{ Rated Capacity } \\
\hline $35 \mathrm{kV}$ & $\begin{array}{l}\text { Wind Farm }(2 \mathrm{MW}) \\
\text { Energy storage unit }(200 \mathrm{~kW})\end{array}$ \\
\hline $10 \mathrm{kV} 1 \#$ & PV power station $(500 \mathrm{~kW})$ \\
\hline $10 \mathrm{kV} \mathrm{2 \#}$ & $\begin{array}{l}\text { PV power station }(500 \mathrm{~kW}) \\
\text { diesel generator }(500 \mathrm{~kW})\end{array}$ \\
\hline
\end{tabular}

Wind farm Wind Power generator has the following three types, including fixed pitch wind turbines, doubly fed wind power generator and direct drive permanent magnet wind turbine generator [5][6]. Fixed pitch wind turbines has the advantages of simple structure, easy to control, but do not have the function of low voltage ride through. At present, the island has this type of wind turbine. In order to ensure the reliable operation of microgrid, it is necessary to convert its structure and function.

Wind turbines can maintain the generator terminal voltage stability and achieve low voltage ride through. The inverter of the machine side is used to maintain constant voltage and frequency, system have stable running in a variety of voltage fluctuation. The inverter of the grid side adopts the typical double loop control strategy. The control block diagram is shown in Fig.2.

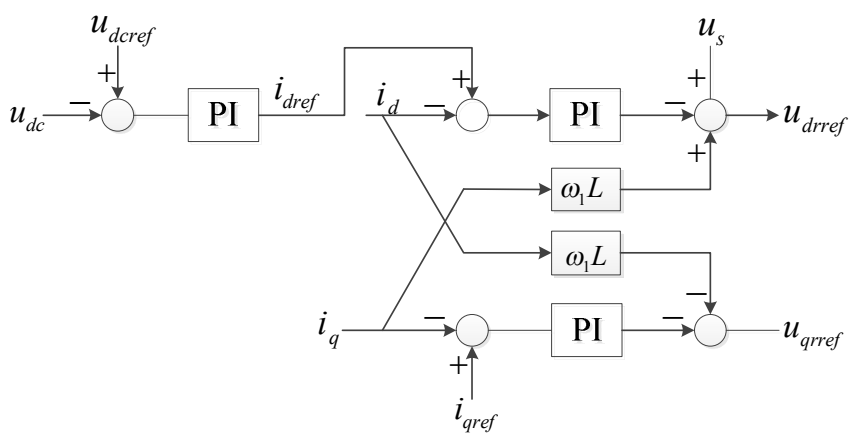

Fig.2 Control block diagram of grid side converter of wind turbines

Among them: id and iq represent current of grid side, Udc represent DC bus voltage of converter, Udcref represent DC bus reference voltage of converter, Udrref、 Uqrref represent current control output values of net side.

Model of energy storage unit Storage converter structure is a three-phase bridge rectifier circuit in the grid of its control can be achieved using PQ island grid "load shifting" flat intermittent intermittent power supply, etc; in the island grid islanding situation, droop control storage unit in 
order to maintain the island grid voltage and frequency stability. Under dq coordinates, PQ control block storage converter is shown as Fig.3.

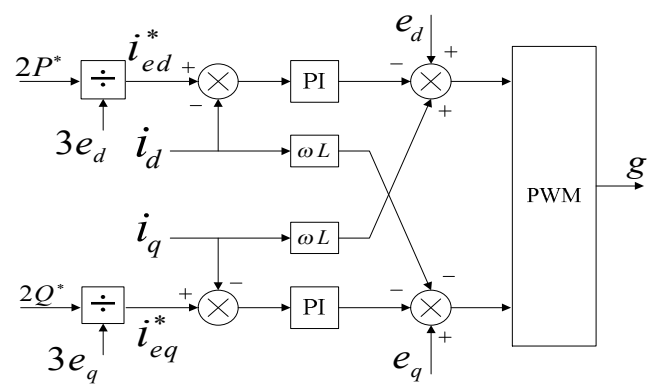

Fig.3 PQ control diagram of energy storage unit

Among them: id 、iq 、 ed and eq represent grid current and grid voltage, $\mathrm{L}$ is reactance, $\mathrm{g}$ is trigger signal of energy storage converter. Under the PQ control mode, the energy storage unit can output constant output active and reactive power according to scheduling instructions [7][8]. In the case of islands, droop control block diagram of the energy storage unit is shown as Fig.4.

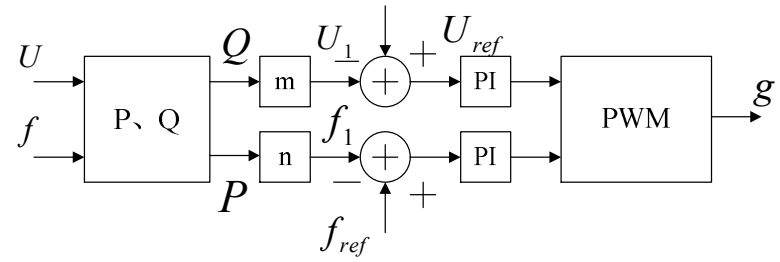

Fig.4 Droop control diagram of energy storage unit

As shown as Fig.6, $\mathrm{m}$ is droop factor of $\mathrm{U}-\mathrm{Q}, \mathrm{n}$ is droop factor of $\mathrm{f}-\mathrm{P}, \mathrm{g}$ is trigger signal of energy storage converter. In the case of islands, droop control block diagram of the energy storage unit can enable the system voltage and frequency droop in order to achieve local control system voltage and frequency.

\section{Grid Connection Control Strategy}

Under the condition of the grid connection, island grid control objective is to confirm stabilizing system of network focal points and maximize the acceptance of new energy generation. So this situation needs energy storage unit work in PQ State [9][10][11]. Real-time power storage unit issued is calculated as follows.

$$
\left\{\begin{array}{l}
P_{E S}=P_{P C C}^{*}-P_{P V}-P_{W F}+\sum P_{\text {load }}+P_{D L} \\
Q_{E S}=Q_{P C C}^{*}-Q_{P V}-Q_{W F}+\sum Q_{\text {load }}-Q_{C}
\end{array}\right.
$$

Among them: PES and QES separately represent active po Among them: PES and QES separately represent active power and reactive power of energy storage unit, $\mathrm{PPCC}^{*}$ and QPCC ${ }^{*}$ separately represent active power and reactive power of grid-connected point, PPV and QPV separately represent active power and reactive power of PV power station, PWF and QWF separately represent active power and reactive power of wind power station, and separately represent active power and reactive power of electric power, PDL represent active power of desalinization plants, QC represent reactive power of submarine cable.

\section{System Test}

Active load changes of island power are shown in Fig.5 during the period of 0-4s. As can be seen from the test results, when the intermittent power fluctuation happen, the system quickly adjust the output power of the energy storage unit to maintain active $110 \mathrm{kV}$ line at around $33 \mathrm{~kW}$ and improve the problem of intermittent power fluctuations island grid. From the Fig.8, the energy storage unit and diesel generator can be coordinated control to ensure the system voltage and frequency stability and also reduces the risk of overloading the storage unit. 


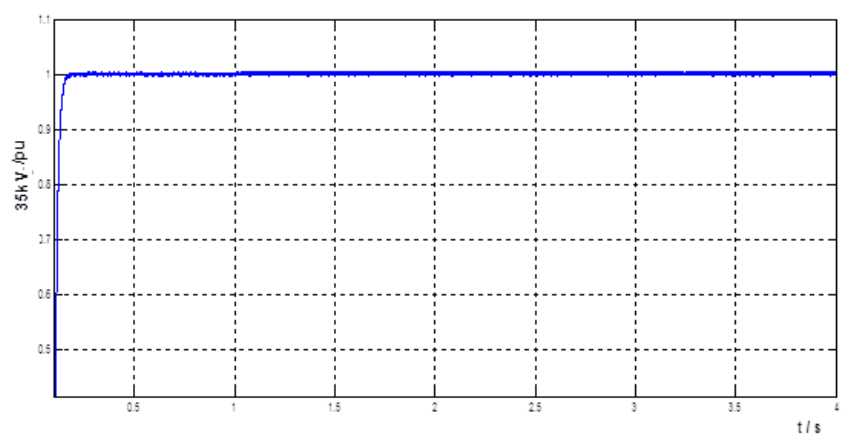

Fig.5 $35 \mathrm{kV}$ bus voltage

\section{Summary}

This paper established a simulation model of intermittent renewable energy island grid and proposed three control strategies in the case of grid connection. Using PSCAD simulation platform, operation control strategies are justified under the conditions of the grid connection and island running. The results show strategies proposed can ensure the system voltage and frequency stability and also reduces the risk of overloading the storage unit.

\section{References}

[1] Li Bihui, Shen Hong, Tong Yong, et al, "Impacts of energy storage capacity configuration of HPWS to active power characteristic and its relevant indices," Power System Technology, vol. 35, Dec. 2001, pp. 123-128.

[2] IEEE standard for interconnecting distributed resources with electric power systems. IEEE Std1547-2003 . 2003.

[3] Lu Zongxiang, Wang Caixia, Min Yong, et al, "Overviewon microgrid research.," Automation of Electric Power Systems, vol. 31,May. 2007, pp. 100-107.

[4] Zhang Mingrui, Du Zhichao, Li Na, et al, "Control strategies of frequency stability for islanding high-voltage microgrids.," Automation of Electric Power Systems, vol. 32, May. 2012, pp. 20-26.

[5] Li Fudong, Wu Min, "An improved control strategy of load distribution in an autonomous microgrid,” Proceedings of the CSEE, vol. 46,Jan. 2011, pp. 18-25.

[6] Wang Cheng-shan, Xiao Zhao-xia,Wang Shou-xiang, "Syn-thetical control and analysis of microgrid," Automation of Electric Power Systems, vol. 32, Dec. 2008, pp. 98-103.

[7] Wang He, Li Guoqing, "Conrol strategy of microgrid with different DG types," Electric Power Automation Equipment, vol. 32,Feb. 2012, pp. 19-23.

[8] Guo Y, Fang Y, "Electricity cost saving strategy in data centers by using energy storage," IEEE Transactions on Parallel and Distributed Systems, vol. 24,May. 2013, pp. 1149-1160.

[9] Amjady N, Keynia F, Zareipour H, "Short-term load forecast of microgrids by a new bilevel prediction strategy," IEEE Transactions on Smart Grid, vol.1,Jan. 2010, pp. 286-294.

[10] Varaiya P P, Wu F F, Bialek J W, “Smart Operation of Smart Grid: Risk -Limiting Dispatch,” Proceedings of the IEEE, vol. 99, Dec. 2011, pp. 40-57.

[11]Zhong Qing, Smart grid key technology research. China electrical power press, 2011 